\begin{tabular}{c|c|c}
\hline \hline Vol. 249: 265-276, 2003 & MARINE ECOLOGY PROGRESS SERIES \\
Mar Ecol Prog Ser & Published March 10 \\
\hline
\end{tabular}

\title{
Diel feeding pattern of whiting in the North Sea
}

\author{
Anna Rindorf* \\ University of Copenhagen, Danish Institute for Fisheries Research, Charlottenlund Castle, 2920 Charlottenlund, Denmark
}

\begin{abstract}
Though numerous studies have analysed the feeding periodicity of North Sea gadoids, no general diel pattern has been found. The lack of agreement between studies may be related to differences in prey composition and behaviour, but it has not been attempted to link the diel intake pattern directly to intake of individual prey. This study presents an analysis of the round the clock occurrence of several prey types in the stomachs of whiting Merlangius merlangus, a major predator on fish and crustaceans in the North Sea. Generalised linear models were used to determine if the occurrence of different prey varied significantly with time of day and whether this diel pattern differed between locations and predator size groups. The results show that the occurrence of bottom dwelling prey increased significantly during the night at 4 of 5 locations. In contrast, free swimming prey and prey migrating towards the demersal layer during the day were eaten mainly in the daylight hours. No diel pattern in the presence of larger fish prey could be found, presumably due to their longer digestion time. A general diel pattern in catch rates of the predator could not be detected and the analyses did not appear to be biased by vertical migration of the predator. The results have important implications for the understanding of prey selection by wild predators, as this is, in effect, a choice between temporally co-occurring prey.
\end{abstract}

KEY WORDS: Diel variation · Prey availability $\cdot$ Prey selection · Diet composition

Resale or republication not permitted without written consent of the publisher

\section{INTRODUCTION}

The diet of predatory fish has received much interest, as knowledge of their functional response can potentially improve our understanding of marine ecosystems. Generally speaking, food intake reflects a combination of prey preferences of the predator and encounter rate with the different prey (Manly et al. 1972, Chesson 1978, Bres 1989, Buckel \& Stoner 2000). Encounter rate is likely to change through the diel cycle as a number of prey species exhibit diel changes in behaviour (Ansell et al. 1999, Bergström 2000, Liljebladh \& Thomasson 2001). Diel changes in total food intake have been examined by combining observations of total stomach content with digestion models (Hall et al. 1995) while changes in food composition have been examined by investigating the amount or occurrence of different prey in stomachs round the clock (Albert 1995, Pillar \& Barange 1997). However, no consistent diel pattern has been found in investigations of food intake of a single species at

*Email: ar@dfu.min.dk different sampling times or locations. Thus, Albert (1995) found haddock Melanogrammus aeglefinus to be feeding mainly in the early morning and late afternoon, whereas Hall et al. (1995) reported a main feeding period from 22:00 $\mathrm{h}$ to $24: 00 \mathrm{~h}$ for this species. Similarly, whiting Merlangius merlangus has been reported to feed mainly in the morning hours by some authors (Hall et al. 1995, Pedersen 2000) while others report feeding to take place during darkness (Patterson 1985, Mergardt \& Temming 1997). Several authors have suggested the discrepancy to be caused by differences in prey density and between the diel patterns of availability of different prey (Singh-Renton \& Bromley 1999, Adlerstein \& Welleman 2000). If this is the case, the pattern for a particular prey should be similar at different locations. Thus, analysing the diel pattern in occurrence of a particular prey at several locations presents a simple test of whether diel food intake patterns are likely to be caused by general changes in availability of different prey.

๑) Inter-Research $2003 \cdot$ www.int-res.com 
Changes in the vertical distribution of the predator have also been mentioned as a possible cause of diel intake patterns (Pedersen 2000). If the population of whiting consists of 2 subpopulations, a vertically migrating subpopulation feeding on pelagic prey and a non-migrating demersal subpopulation feeding on demersal prey, diel patterns may be detected in the stomach content even when none of the separate subpopulations change their feeding over the course of the day. When the vertically migrating fish are absent from the demersal layer, non-migrating fish will dominate demersal trawl catches and demersal prey will be abundant in the stomach content of the fish caught. If the vertical migration follows a particular diel pattern, stomach analyses of demersally caught fish may reveal a diel pattern in the occurrence of pelagic and demersal prey that is not caused by changes in intake. As the number of non-migrating fish caught by demersal trawling should be relatively constant, large catches are likely to be caused by vertically migrating fish in the demersal layer. The occurrence of the prey types should therefore be correlated to the number of predators caught.

This study presents an analysis of the occurrence of a number of prey types in the stomachs of over 7500 whiting sampled at 5 locations in the North Sea. Whiting is a major predator on smaller fish and crustaceans in the North Sea (Hislop et al. 1991) and thus of substantial interest to modellers of the North Sea community dynamics. The diel pattern in occurrence of each of a number of prey types was investigated through generalized linear models as was the difference in this diel pattern between the 5 locations and 3 predator size groups. Furthermore, the catch of predatory whiting was examined to determine if a general pattern could be discerned. This was to establish whether occurrence of any of the prey types was correlated with catch of the predator. These 2 investigations should help to clarify whether an observed diel pattern is likely to be caused by changes in availability of the different prey, or in catchability of a vertically migrating subpopulation of the predator.

\section{MATERIALS AND METHODS}

Data collection. Details of the sampling procedure can be found in Rindorf (2002). Briefly, whiting were caught by bottom trawling at 5 locations in the North Sea in early September 1988 (Locations 1 and 2) and 1989 (Locations 3, 4 and 5) (Fig. 1). Locations differed both in depth $(44,46,53,73$ and $137 \mathrm{~m}$ at Locations 1 to 5) and temperature $\left(16.7,13.7,10.6,8.2\right.$ and $8.6^{\circ} \mathrm{C}$ at Locations 1 to 5). One haul was taken every $4 \mathrm{~h}$ in a total of between 48 and $72 \mathrm{~h}$ at each location. Stomachs of whiting were collected by length stratified sam-

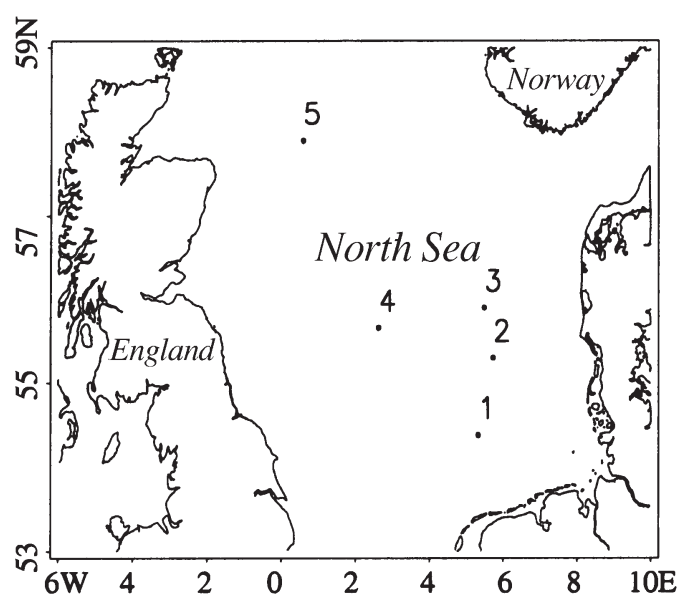

Fig. 1. Map of sampling locations

pling; when available, 50 stomachs from each $5 \mathrm{~cm}$ group were sampled. In total, stomachs from 7738 whiting (length 20 to $35 \mathrm{~cm}$ ) were examined. To ensure a reasonable number of observations for each combination of time, location and size of the predator, the predators were grouped in the length intervals $20-24.5 \mathrm{~cm}, 25-29.5 \mathrm{~cm}$, and $30-34.5 \mathrm{~cm}$. From now on, the size groups are referred to by their midpoints.

A number of fish regurgitate their stomach contents when caught in a trawl and hauled to the surface (Hislop et al. 1991, Robb 1992). Whiting which had flaccid stomachs or food in the mouth or pharynx were therefore assumed to have regurgitated at least part of their stomach contents such whiting were discarded and another whiting of the same length was selected at random from the trawl catch. Whiting stomachs which did not show signs of regurgitation were frozen separately as quickly as possible. In the laboratory the recognizable contents were assigned to species (fish) or major groups: shrimp, crab, krill, 'other crustaceans' and 'other benthic invertebrates'. These groups were chosen both for practical convenience when examining stomach contents, and because they reflect the predator's different feeding modes. Prey in advanced stages of digestion were unlikely to provide information on diel intake patterns, and prey that were too digested to be identified to species or group were therefore excluded from further analyses. The small number of prey in pristine condition which had presumably been eaten in the trawl were also excluded.

Data analyses. The stomach contents of fish which regurgitated was assumed to be similar to that of the non-regurgitating fish, caught in the same haul (Robb 1992). The proportion of stomachs containing food before the fish were caught, $p_{\mathrm{f}}$, is therefore calculated as:

$$
p_{\mathrm{f}}=\frac{n_{\mathrm{r}}+n_{\mathrm{f}}}{n_{\mathrm{r}}+n_{\mathrm{f}}+n_{\mathrm{e}}}
$$


where $n_{\mathrm{r}}$ is the number of stomachs from which the contents were regurgitated, $n_{\mathrm{f}}$ is the number of stomachs which contained food and showed no signs of regurgitation and $n_{\mathrm{e}}$ is the number of stomachs which neither contained food nor showed signs of regurgitation (Hislop et al. 1991). The occurrence of given prey in the stomachs prior to regurgitation of contents, if this happens at all, is defined as $p_{\text {prey }}$ and can be calculated as:

$$
p_{\text {prey }}=\frac{n_{\text {prey }}}{n_{\mathrm{r}} / p_{\mathrm{f}}}
$$

where the number of stomachs containing a given prey is $n_{\text {prey }}$. This occurrence can also be regarded as the probability that a stomach contains this prey prior to hauling the fish to the surface. The probability can be analysed by methods applicable to binomial distributed variables. The number of binomial trials is $n_{\mathrm{f}} / p_{\mathrm{f}}$ and the number of positive outcomes is $n_{\text {prey }}$. Generalized linear models can be used to test whether the probability varies over time, between predator size groups or between locations (McCullaugh \& Nelder 1989, Stefánsson \& Pálsson 1997).

A model of the probability of a stomach containing particular prey should include differences between locations and predator size groups as well as diel variation. The model should also facilitate tests for interaction effects, i.e. differences between locations and predator size groups. Finally, it should be possible to test for trends in occurrence over the sampling period. These demands are met by a generalized linear model which applies the logit link function to the probability $p$ that a stomach contains a particular prey group (Stefánsson \& Pálsson 1997):

$\ln \left(\frac{p_{l o c, t, l, T}}{1-p_{l o c, t, l, T}}\right)=a_{l o c}+b_{t}+c_{l}+a b_{l o c, t}+a c_{l o c, l}+b c_{t, l}+d_{l o c} T$ where loc denotes location, $t$ is time of day (GMT, 6 times of day sampled), $l$ is predator length group, $T$ is the time in $h$ passed between midnight before the first day of sampling and the time at which the particular haul was taken and $a, b, c, a b, a c, b c$ and $d$ are constants within indices to be estimated in the model. If $d$ differed significantly from zero at any location, a trend in occurrence was recorded. Apart from the trend with time of sampling, this is, in essence, an analysis of variance (ANOVA) as no other continuous effect is inserted. If the variable $a b_{l o c, t}$ does not differ significantly from zero, the diel pattern is similar at all locations. In parallel, if $c b_{t, 1}$ does not differ significantly from zero, the same diel pattern is found for all predator length groups.

When a trend was found $\left(d_{l o c} \neq 0\right)$, predictions of probabilities round the clock required the selection of a particular sampling time to standardise values with respect to the trend. Hence the probability for the spe- cies in which a significant trend was found was estimated for all times of day, inserting the midpoint of the sampling interval for $T$.

One model was fitted for each of the following prey groups: shrimp, crab, krill, 'other crustaceans', 'other benthic invertebrates', herring Clupea harengus, sprat Sprattus sprattus, dab Limanda limanda, and whiting. These species and groups were chosen as they occurred in more than 5 stomachs at all times of day at 2 or more of the locations. Krill posed a special problem as it disappeared completely after 24, 31 and $42 \mathrm{~h}$ at Locations 1, 3 and 4, respectively. As this complete lack of positive outcomes bias the tests used when reducing the models (McCullaugh \& Nelder 1989), only the first part of the sampling period was used for krill at these locations.

Analysis of catch rates. The natural log of the catch in numbers of each size group in each haul was calculated and an analysis of variance (ANOVA) was performed to determine if the catch varied significantly with time of day at any of the locations and whether this diel pattern differed between locations. The geometric average of the catch in numbers of each size group at each time and location was calculated.

Correlation between the proportion of stomachs containing a particular prey and the catch of whiting. Diel variation in catch rate may be caused by a varying number of more pelagic whiting caught together with a more or less constant number of demersal whiting (Pedersen 2000). If such vertical migration takes place and the diet of the demersal whiting differs from that of the more pelagic whiting, a correlation between the proportion of stomachs containing a given prey and the trawl catch of whiting should be detectable. The correlation should be negative if the prey was primarily present in the stomachs of the demersal proportion of the population and positive if the prey was primarily present in the stomachs of the pelagic proportion of the population. No correlation would suggest that the diel change in occurrence of the particular prey was caused by factors other than differential diets combined with catches of a vertically migrating subpopulation. The correlation between the occurrence of each prey in a predator length group and the natural log of the average catch in numbers of this predator length group was therefore calculated. One correlation was calculated for each location, predator length group and prey group for the prey where occurrence varied with time of day and predator size. All correlations were tested for significance at $\alpha=0.05$.

Statistical analyses. All statistical analyses were performed using SAS ${ }^{\circledR}$ version 8 for Windows ${ }^{\circledR}$. The scale parameters of the generalised linear models were estimated by the Pearson statistic to allow for overdispersion. As this procedure invalidates tests of model fit, 
these were not performed. Factors not having a significant effect at the $5 \%$ level ( $F$-statistic) were eliminated from the models.

\section{RESULTS}

\section{Analysis of stomach contents}

The prey groups as well as the location and length groups included in analyses for each prey can be seen in Table 1. Apart from the prey types already mentioned, a number of prey types occurred in the stomachs at 1 location only. As analyses of the occurrence of these prey would not provide information on general diel intake patterns, they are not mentioned further in this study. The shrimps found were a mixture of Pandalus and Crangon spp. The prey group 'other crustaceans' contained both copepods, amphipods and isopods as well as unidentified crustaceans which may have been remains of one of the other crustacean groups. The prey 'other benthic invertebrates' were mainly polychaetes, hermit crabs and brittle stars with some molluscs and Norway lobsters Nephrops norvegicus.

The fit of the models was generally good, with the residual deviation adequately described by random variation in a binomial distribution in most cases (the dispersion parameter was close to 1 [McCullaugh \& Nelder 1989]) (Table 2). Explanation of deviance ranged from 0 to $88 \%$ (mean $64 \%$ ) by models with between 1 and 42 parameters (Table 2). More than half the species exhibited significant trends in the probability of occurring in a stomach over the sampling period at least at 1 of the locations (parameter $d_{l o c}$ was significantly different from zero). Three selected examples of such trends are given in Fig. 2. For the prey groups in
Table 1. Prey groups and positions and predator length groups included in analysis of the probability of a stomach containing each prey group

\begin{tabular}{|lcccccc|}
\hline \multirow{2}{*}{ Prey group } & \multicolumn{7}{c|}{ Location } \\
& 1 & 2 & 3 & 4 & 5 \\
\hline Dab Limanda limanda & $\times^{\mathrm{b}}$ & $\times^{\mathrm{a}}$ & $\times^{\mathrm{b}}$ & & \\
Herring Clupea harengus & $\times$ & $\times$ & $\times$ & & \\
Sprat Sprattus sprattus & $\times^{\mathrm{a}}$ & $\times^{\mathrm{a}}$ & & & \\
Whiting Merlangius merlangus & & & $\times^{\mathrm{b}}$ & & & \\
Krill & $\times$ & $\times$ & $\times^{\mathrm{b}}$ & $\times^{\mathrm{b}}$ & \\
Shrimp & $\times$ & $\times$ & & & $\times$ \\
Crab & $\times$ & $\times$ & $\times$ & $\times$ & \\
'Other crustaceans' & $\times$ & $\times$ & $\times^{\mathrm{b}}$ & $\times$ & $\times$ \\
'Other benthic invertebrates' & $\times$ & $\times$ & $\times$ & $\times$ & $\times$ \\
aOnly length groups 27.5 and 32.5 & & & & & & \\
'Only length groups 22.5 and 27.5 & & & & & \\
\hline
\end{tabular}

which values of $\mathrm{d}_{l o c}$ were found to be significantly different from zero, both negative and positive trends were recorded for all groups but 2. At 3 locations, positive trends were recorded for 'other crustaceans' and negative trends for krill, whereas no trend was found at the remaining locations. If positive and negative significant trends are equally likely, the probability of obtaining 3 trends in the same direction by chance is 0.13 .

Diel variation in the proportion of stomachs containing particular prey was found for 7 of the 9 prey types and selected examples of observed and predicted probabilities are seen in Fig. 3. The diel pattern did not vary with predator size, i.e. the parameter $f_{t, l}$ was not significantly different from zero for any prey group (Tables $2 \& 3$ ). The prey groups for which the majority of the diel variation could be explained by a common pattern included crabs, 'other benthic invertebrates' and to some extent dab (Figs. 4 \& 5). Dab was found primarily at night at all locations, though the exact tim-
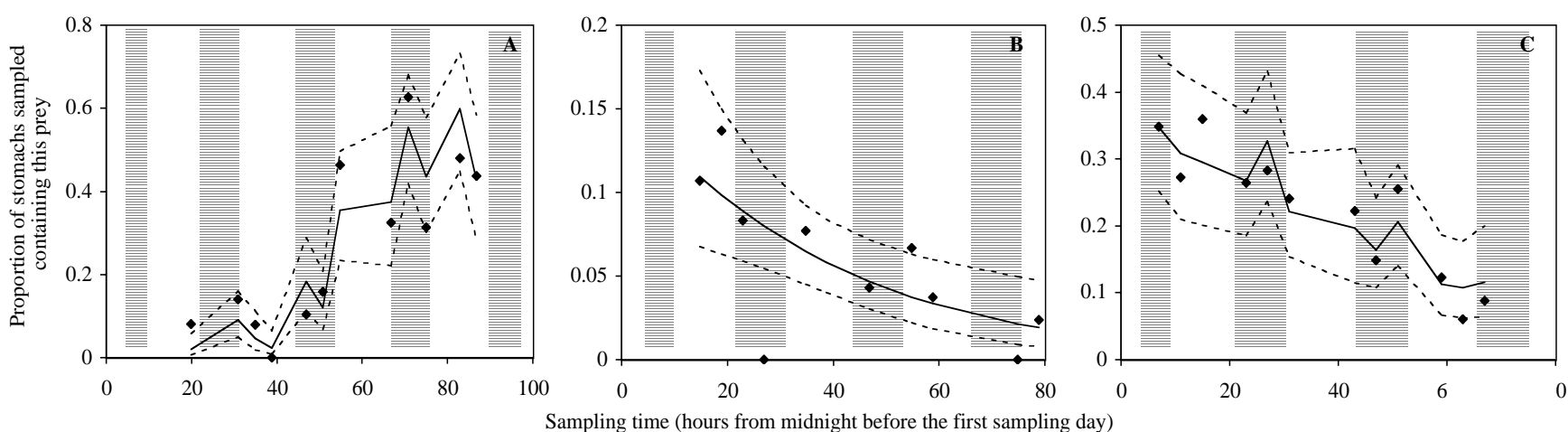

Fig. 2. Trends in the observations ( $\bullet)$, reduced model estimates (-) and the $95 \%$ confidence limits of the estimate (- - - -) of proportion of the stomachs containing (A) other crustaceans (predator length 20 to $25 \mathrm{~cm}$, Location 3), (B) herring (predator length 30 to $35 \mathrm{~cm}$, Location 2) and (C) whiting (predator length 20 to $25 \mathrm{~cm}$, Location 5) over the sampling period. Shaded areas indicate night periods 

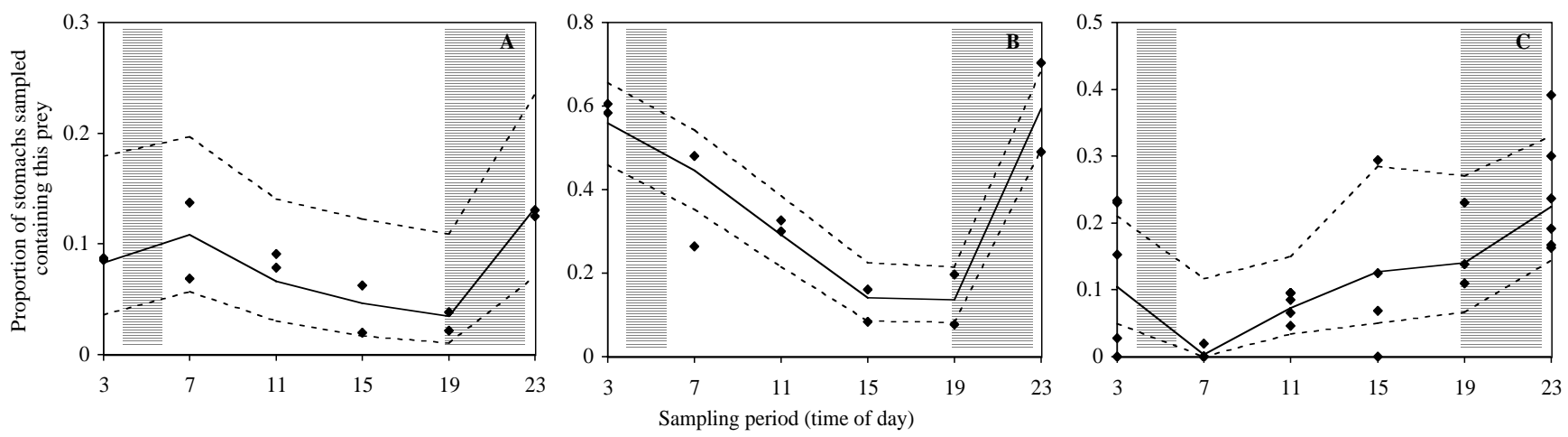

Fig. 3. Observations ( $\bullet$, reduced model estimates $(-)$ and the $95 \%$ confidence limits of the estimate (-- - ) of proportion of the stomachs containing (A) 'other benthic invertebrates' (predator length 25-30 cm, Location 4), (B) crab (predator length 25-30 cm, Location 3) and (C) shrimp (all predator lengths, Location 2) as a function of time of day. Shaded areas indicate night periods

ing of the peak may vary somewhat (Fig. 5A). A second peak was found in the late morning hours, ranging from 07:00 h at Location 3 to $11: 00 \mathrm{~h}$ at Locations 1 and 2. The diel patterns for the prey group 'other benthic invertebrates' at Locations 1 to 4 were not significantly different. At Location 5, there was no significant diel variation in the occurrence of 'other benthic invertebrates', and this led to a significant difference in diel pattern between the locations. The common diel pattern for crabs explained $31 \%$ of the deviance, and adding the differences in diel patterns between locations only increased the explained deviance by another $5 \%$ (Table 4 ).

The diel variation in the occurrence of whiting in the stomachs was not significant at Location $5(\mathrm{p}=0.3350)$, whereas a peak around midday was found at Location 3 (Fig. 4A-C). Krill seemed to be ingested primarily around dawn and in the early afternoon until some time after dusk (Fig. 4D-F). The patterns found at Locations 2, 3 and 4 were not significantly different, whereas the pattern found at Location 1 was somewhat erratic and highly significant. No general diel pattern could be found for 'other crustaceans' (Fig. 4J-L) and no diel difference in the occurrence of herring and sprat was detected (Table 2). No significant diel variation in the occurrence of shrimp was found at Location 5 (Fig. 5B), and the pattern at Location 1 was greatly affected by 2 very high occurrences observed at 03:00 and 11:00 h. A more consistent diel pattern was found at Location 2 throughout the sampling period (Fig. 3C). Here, shrimp appeared to be eaten in the daylight hours and into the early evening. A correlation analysis revealed that the proportion of total deviance explained by time of day for a particular prey group was significantly negatively correlated to the mean weight of the prey group present in the stomach (Table 4, correlation $=-0.78, \mathrm{p}=0.012, \mathrm{n}=9$ ). The occurrence of herring was virtually linearly related to predator length, increasing by $3.4,2.5$ and $4.2 \%$ as predator length increased by $5 \mathrm{~cm}$ at Locations 1,2 and 3 , respectively.

\section{Analysis of diel variation in catch rates}

Though significant diel variation in catch rates within each location was found, no common diel pattern could be detected for any of the size groups ( $p>0.26$ for all length groups). Catches were higher in the daytime for some size groups at Locations 2 and 4 , while no obvious pattern was found at the remaining locations (Fig. 6).

\section{Correlation between the proportion of stomachs containing a particular prey and the number of whiting caught}

Three of the analyses revealed significant correlations between the proportion of stomachs containing prey and ln (number of whiting caught) within a length group and location. However, 53 analyses revealed no significant correlation between these 2 parameters. $5.4 \%$ of the analyses revealed significant correlations between these parameters, which is less than may occur from a type II error in a test with a significance level of $5 \%$ (56 tests performed). Thus, in total, no significant correlation between the proportion of stomachs containing particular prey and the number of whiting caught was found.

\section{DISCUSSION}

The analyses showed that the diel pattern of occurrence of some prey groups varied little with location in 


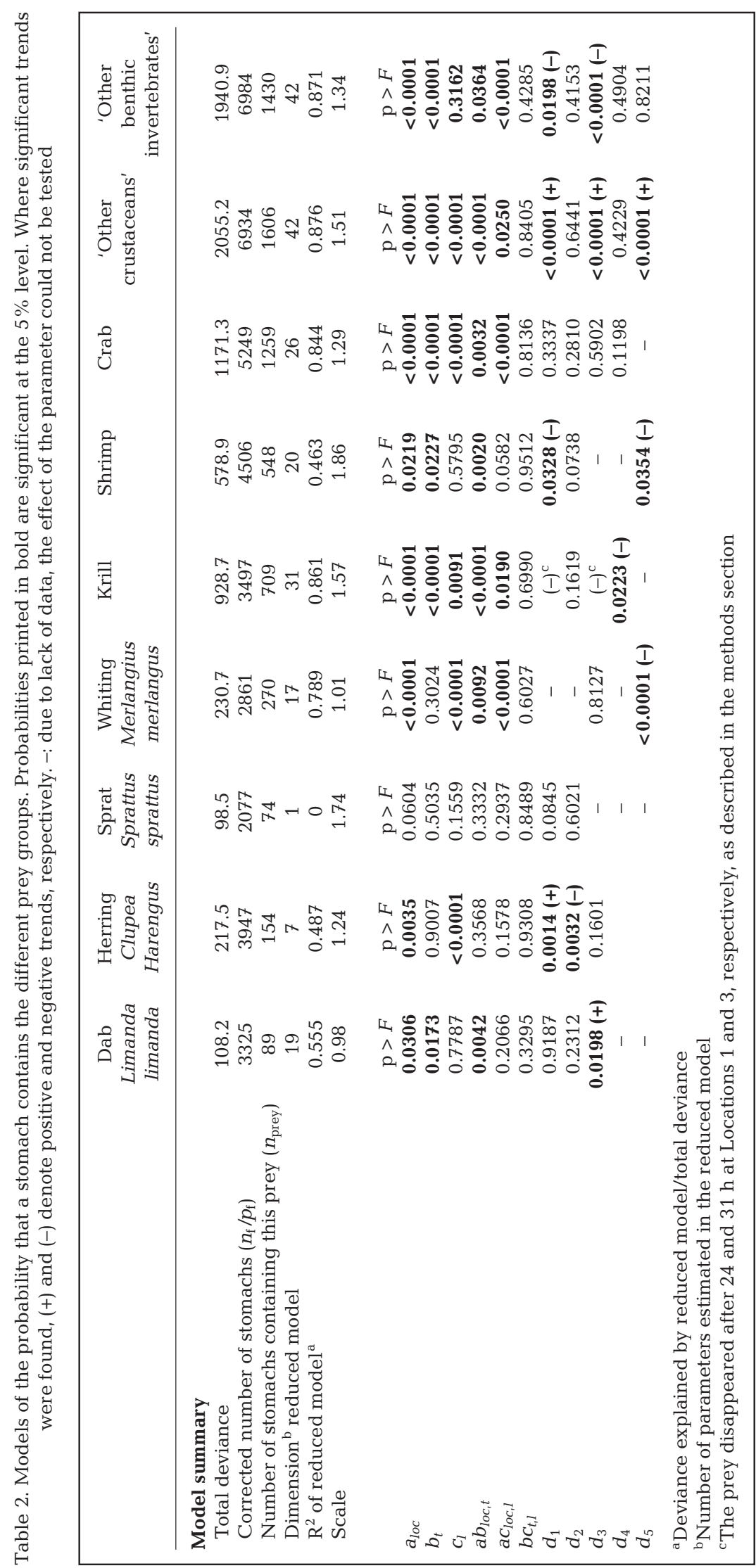

spite of the great differences in depth and temperature between locations. In particular, bottom dwelling prey appeared to be eaten mainly at night and in the early morning hours whereas shrimp, krill, 'other crustaceans' and, to some extent, whiting, were eaten during the day and in the early evening. No diel pattern in the occurrence of the larger prey, herring and sprat, was found. However, the proportion of the total deviance which could be explained by time of day for a particular prey group was significantly negatively correlated to the mean weight of the prey group present in the stomach, and the lack of diel variation in the proportion of stomachs containing large fish prey may have been caused by the inability of the method to detect this in larger prey. This problem is most probably caused by the prolonged digestion times of large prey (Andersen 1999).

The change in occurrence of the different prey groups with size of the predator mirrors that found in other investigations (Jones 1954, Gordon 1977, Bergstad 1991, Hislop et al. 1991, Pedersen 1999). Invertebrate prey becomes progressively less important as predator size increases (Fig. 4). However, whereas other studies have reported the occurrence of fish prey to increase with predator size, in the present study this trend could only be detected for herring.

Bottom dwelling prey (crabs, 'other benthic invertebrates' and dab) were all eaten mainly at night and the differences in diel patterns between locations were small. The low occurrence of 'other benthic invertebrates' and crabs during daylight was therefore likely to have been a reflection of diel changes in availability. This was supported by the fact that several species of crabs (Liocarcinus sp., Carcinus sp.) have been shown to feed mainly at night, and some species have been observed to bury during the daytime (Naylor 1958, Freire et al. 1991, Ansell et al. 1999). Of the prey categorised as 'other benthic invertebrates', some species of brittle stars have been shown to be mainly nocturnal (Basch 1988 in Sköld 1998, 

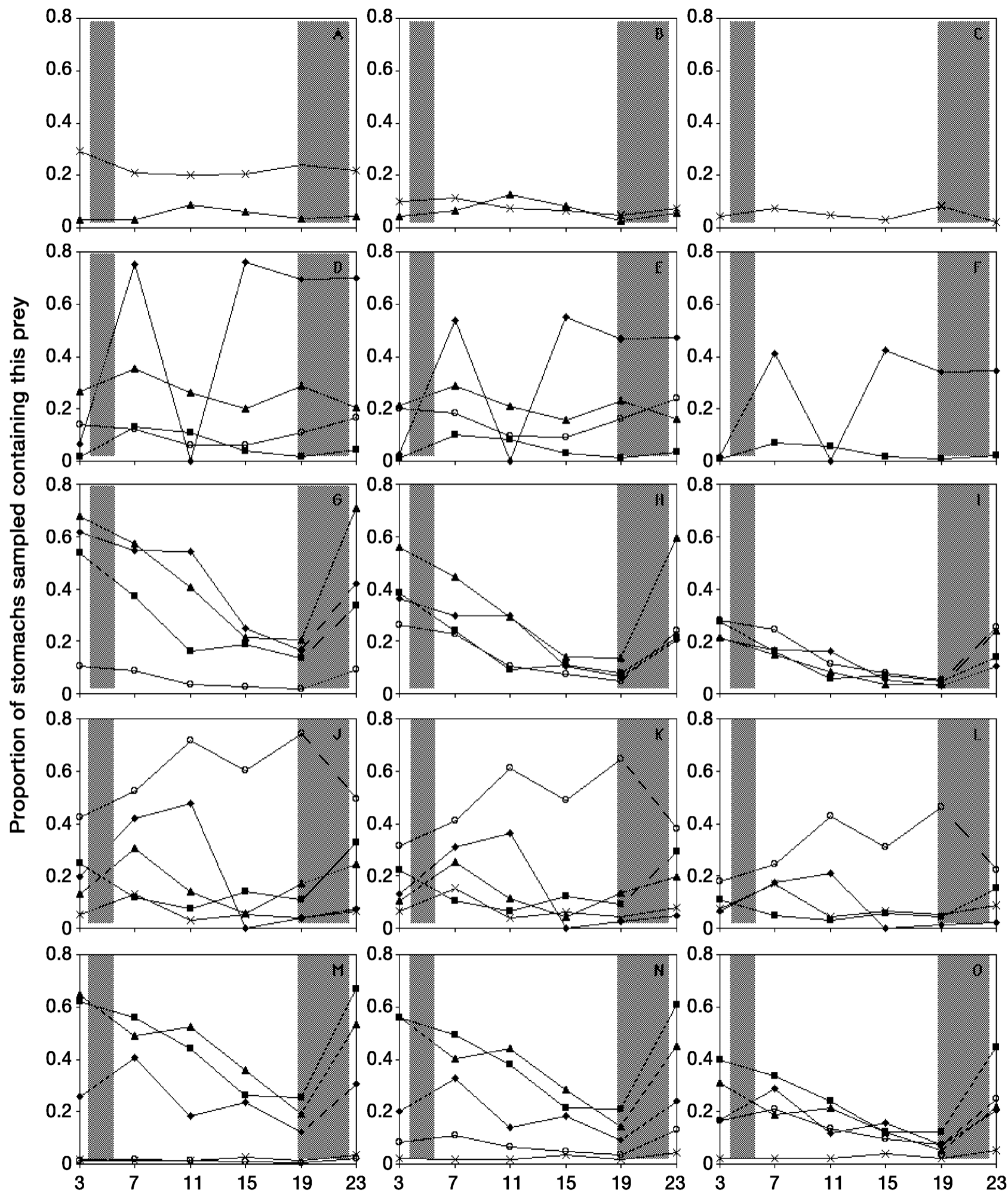

Sampling period (time of day)

Fig. 4. Comparison of diel patterns in model estimates of the probability of the stomach containing particular prey at the 5 locations

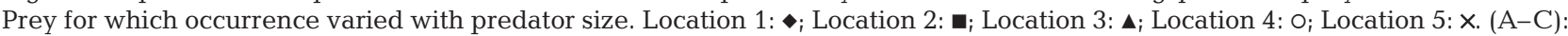
Whiting, (D-F): krill, (G-I): crab, (J-L): 'other crustaceans', (M-O): 'other benthic invertebrates'. Predator lengths 20-25 cm (A, D, G, J and M), 25-30 cm (B, E, H, K and N) and 30-35 cm (C, F, I, L and O) 


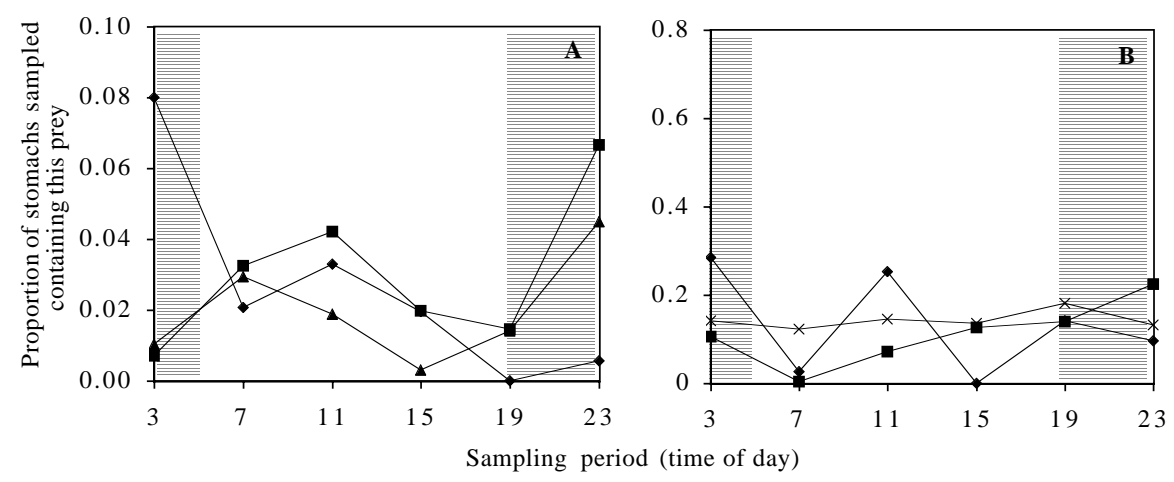

Fig. 5. Comparison of diurnal patterns in model estimates of the probability of the stomach containing a given prey at the 5 locations. Prey for which occurrence did not vary with predator size. Location 1: ; Location 2: $\mathbf{m}$; Location 3: $\boldsymbol{\Lambda}_{i}$ Location 5: $\times$. (A) Dab. (B) Shrimp. Note that scale of A is different from that of B
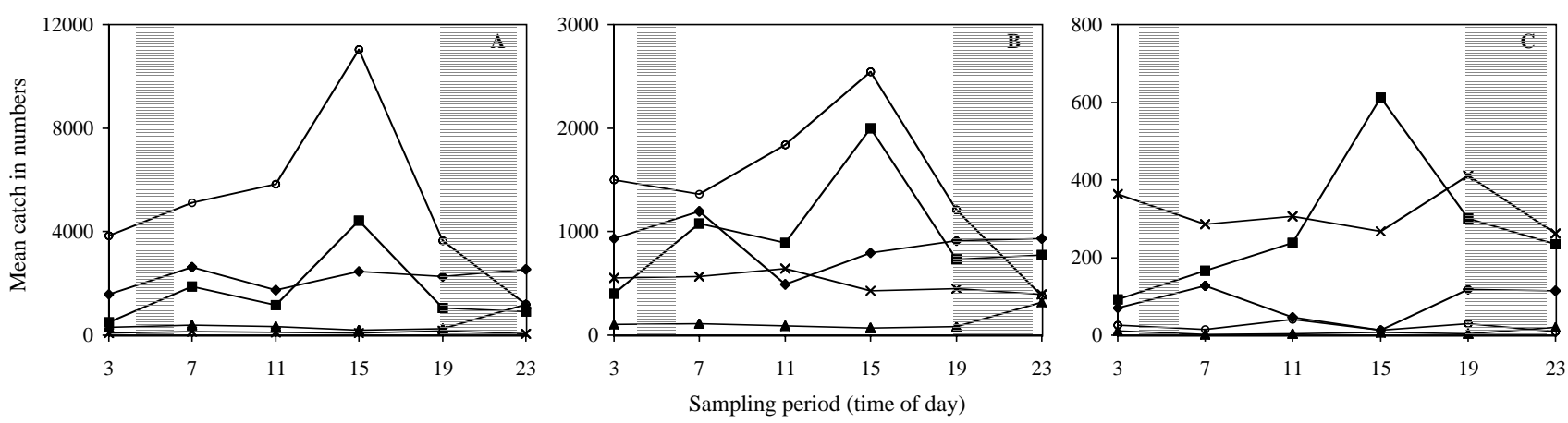

Fig. 6. Mean catch in numbers as a function of time of day. Location 1: $\bullet$; Location 2: $\mathbf{m}$; Location 3: $\mathbf{\Lambda}_{\text {; }}$ Location 4: O; Location 5: $\times$. Predator lengths $20-25 \mathrm{~cm}(\mathrm{~A}), 25-30 \mathrm{~cm}(\mathrm{~B})$ and $30-35 \mathrm{~cm}(\mathrm{C})$

Table 3. Reduced models of the probability that a whiting stomach contains the given prey. Definition of the parameters are given in the text

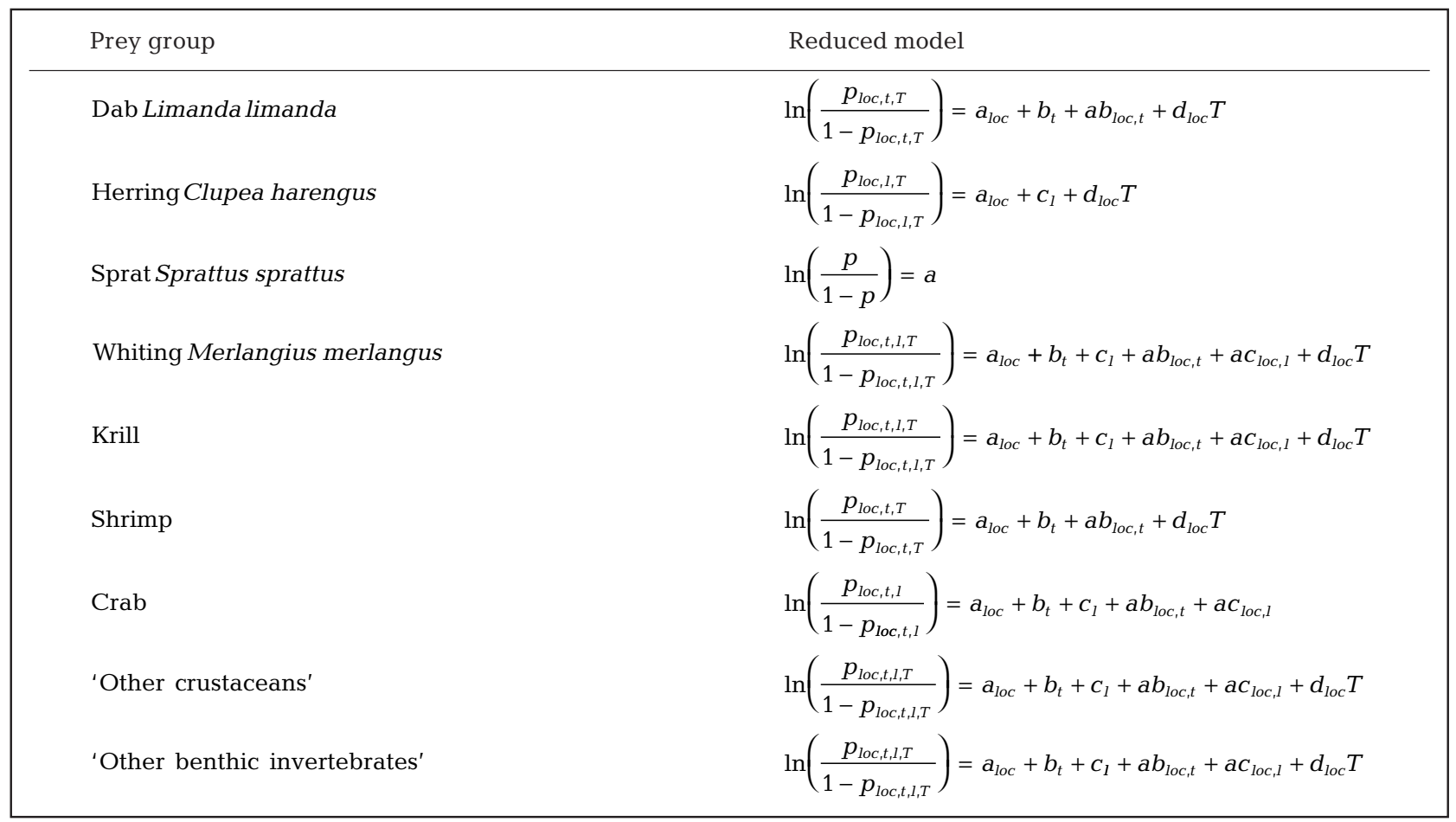


Rosenberg et al. 1997), whereas other species exhibit escape reactions to visual stimulation (Sköld 1998) and may be less easily caught during daylight.

In contrast to bottom dwelling prey, krill appear to have been eaten around dawn and in the afternoon and early evening hours. Krill migrate towards the surface at night while daylight hours are spent in the lower pelagic or demersal layers (Onsrud \& Kaartvedt 1998, Tarling et al. 2000, Liljebladh \& Thomasson 2001). The ascent to the pelagic appears to take place around $1 \mathrm{~h}$ after sunset, whereas the descent occurs at dawn (Liljebladh \& Thomasson 2001) and this was reflected in the intake of this prey (dawn to some hours after dusk). The intake around midday was limited, perhaps indicating that krill is more vulnerable during the period of ascent and descent. Krill appeared to be a patchily distributed prey as some periods were categorised by complete lack of krill in the stomach contents.

Variation in the contribution of copepods, amphipods, isopods and unidentified crustaceans to the group of 'other crustaceans' may lead to great differences in the diel pattern as their behaviour differs markedly (Ansell et al. 1999, Bergström 2000, Liljebladh \& Thomasson 2001). It is therefore not surprising that no common diel pattern in the occurrence of this prey group was found. However, the occurrence generally did not increase during darkness. The shrimps found differ in diel behavioural patterns. Pandalus montagui and $P$. borealis, the 2 major Pandalus species in the area, ascend into the pelagic layer at night but spend the day at or near the bottom (Bergström 2000), whereas Crangon crangon is more active during the night and spends part of the daylight hours buried in the sediment (Hagerman 1970, Ansell et al. 1999). Unfortunately, the shrimp were not identified to species, but $P$. montagui is present in the area around Location 2, and the diel intake pattern mirrors the demersal availability of this species (Bergström 2000).

Table 4. Mean weight of the prey group and proportion of total deviation $\left(\mathrm{R}^{2}\right)$ explained by the model and diurnal differences $\left(b_{t}\right.$ and $\left.a b_{l o c, t}\right)$ after eliminating insignificant effects

\begin{tabular}{|lcccc|}
\hline Prey group & \multicolumn{4}{c|}{$\mathrm{R}^{2}$ of } \\
& $\begin{array}{c}\text { Reduced } \\
\text { model }\end{array}$ & $b_{t}$ & $a b_{l o c, t}$ & $\begin{array}{c}\text { Mean } \\
\text { weight }(g)\end{array}$ \\
\hline Dab Limanda limanda & 0.55 & 0.17 & 0.21 & 1.36 \\
Herring Clupea harengus & 0.49 & 0 & 0 & 8.26 \\
Sprat Sprattus sprattus & 0 & 0 & 0 & 9.27 \\
Whiting Merlangius merlangus & 0.78 & 0.07 & 0.07 & 3.36 \\
Krill & 0.861 & 0.093 & 0.219 & 0.12 \\
Shrimp & 0.46 & 0.11 & 0.29 & 0.80 \\
Crab & 0.84 & 0.31 & 0.05 & 0.29 \\
'Other crustaceans' & 0.88 & 0.01 & 0.13 & 0.20 \\
'Other benthic invertebrates' & 0.87 & 0.11 & 0.03 & 0.66 \\
\hline
\end{tabular}

Whiting appeared to be eaten mainly during daylight hours at Location 3, whereas no pattern was detected at Location 5. The results of investigations on vertical migration of whiting differ, but most authors conclude that small whiting are pelagic and do not migrate vertically in July and August (Bailey 1975, Robb 1981, Bromley \& Kell 1995). In the present study, the biomass of whiting smaller than $14 \mathrm{~cm}$ (the length of the largest whiting prey recorded in the stomachs) caught in the trawl at Location 3 was slightly higher at night than during daylight, but the difference was not significant. Therefore it does not appear that the diel pattern in occurrence of this prey can be explained by differences in demersal density. Rather, free swimming prey as juvenile whiting may be difficult to capture without the aid of vision.

No difference in diel pattern of intake with predator length was found for any prey type. This supports the idea that diel intake patterns are regulated by changes in availability of the prey rather than by sizedependent changes in the diel behaviour of the predator. However, the change in the overall occurrence of invertebrates and, to some extent, fish prey with the size of the predator must have been the result of changes in either the ability to capture larger prey, in prey preferences or in sensory abilities of the predator.

Location 5 differed from the other locations, as significant diel variation was only found in the prey group 'other crustaceans'. No significant diel variation was found for 'other benthic invertebrates', whiting and shrimp, though the occurrence of these was found to vary at other locations. The lack of diel variation in the occurrence of shrimp and whiting may have been caused by the prolonged digestion times in the colder environment at Location 5. However, both ambient temperature and mean weight of the prey 'other benthic invertebrates' were similar at Locations 4 and 5, and as diel variation was found at the former location, these factors cannot have been responsible for the lack of variation at the latter. The occurrence of 'other benthic invertebrates' was low at all times at Location 5, and a diel pattern would probably have been difficult to detect, if it were present. The lack of 'other benthic invertebrates' was mirrored by the virtual absence of both crabs and flatfish, suggesting perhaps that whiting at this location did not forage on the bottom or that the density of benthic prey was low. The lack of benthic foraging may have been linked to the greater depth of this location. 
The lack of a general diel pattern in catch rates supports the findings of Ehrich \& Gröger (1989), who reported that catches of whiting did not vary significantly with time of day. A tendency to catch more whiting during the day was noted by Pedersen (1999), though he does not state whether the difference was significant. The higher catches in daylight of gadoid species have been attributed both to the effect of visual herding by the trawl doors and to changes in vertical distribution (Michalsen et al. 1996). As catch rates of whiting in the prelagic trawls decreased during daylight (Pedersen 1999), the changes in demersal catch rates of whiting may be at least partly caused by changes in vertical distribution. However, the tendency to perform vertical migration (or the effect of visual herding) appeared to vary between locations and with size of the predator (Fig. 6), and in most cases, no evidence of vertical migration was found. Pedersen (1999) suggested that the total population of whiting was divided into subpopulations specializing in different prey. Changes in the proportion of stomachs containing particular prey may therefore reflect changes in the proportion of fish caught belonging to each subpopulation, rather than diel changes in the intake of average fish. In the present study, no significant correlation between the occurrence of different prey and the catch rate of the predator was found (apart from what can be expected by a type II error). Moreover, the general diel pattern in occurrence of benthic prey was also found at Locations 1 and 3 where no diel variation in catch rates was evident. The diel changes in occurrence cannot therefore be explained by vertical migration of different subpopulations of whiting.

The method used here may be affected by a number of problems. Firstly, although it is obvious that a number of whiting must have ingested prey when the proportion of stomachs containing this prey increases significantly from one time point to the next, a fall in the proportion does not reveal whether some ingestion of new prey has taken place along with the digestion of previously ingested prey. Nevertheless, the main periods of consumption of particular prey are the periods in which the proportion of stomachs containing this prey increases. Because digestion rates and amount of each prey present in the stomachs round the clock are not included in the present model, the method cannot be used to estimate the quantitative importance of each time of day in the total ingestion of a given prey. Only the times of day when a large proportion of the predators have fed on a given prey can be revealed.

A number of fish species have been shown to avoid fishing vessels and fishing gear (Ona \& Chruickshank 1986, Ona \& Toresen 1988, Aglen \& Misund 1990). Fur- thermore, the species caught by the trawl may theoretically be locally depleted if high numbers are caught and no significant migration into the area takes place. In both these cases, the density of predators as well as the local availability of prey may decrease during the sampling period. However, if local depletion posed a general problem, the occurrence of the depleted prey should exhibit a negative trend at all locations. As no significant common trend was found, there is no indication of sampling effects on the occurrence in the stomachs of any of the species. The observed trends must have been caused by changes in local abundance or in the appetite of the predators, due to factors unrelated to the sampling procedure. Note that the lack of significant common trends may also have been caused by the low number of locations examined, so care should be taken not to over-interpret this result. No trend in the catches of the predator was found, and there does not appear to be a local depletion of the population though the trawl tracks were laid out in close proximity.

In conclusion, whiting at 4 of the 5 locations were feeding on bottom dwelling prey at night, whereas pelagic and free swimming prey were captured mainly during daylight. This pattern could be due either to the ability of the bottom dwelling prey to avoid the predator during daylight, the increased availability of other prey during the day, or the necessity of vision to capture-success of free swimming prey. Similarly, Gordon (1977) reported a decrease in the occurrence of fish prey in stomachs of small whiting during the night, whereas the occurrence of crustaceans increased. Pedersen (2000) found that demersal whiting fed primarily during daylight hours. The depth and bottom temperature at the location sampled in Pedersen's study were $90 \mathrm{~m}$ and $6^{\circ} \mathrm{C}$, respectively, and around $85 \%$ of the stomach content (by weight) of whiting between 20 and $35 \mathrm{~cm}$ was fish prey. The results may therefore be comparable to those at Location 5 where virtually no bottom invertebrates, crabs and flatfish occurred in the stomachs. Nighttime ingestion is therefore expected to be low and this corresponds well with the results of Pedersen (1999). Adlerstein \& Welleman (2000) found that cod Gadus morhua were eating invertebrates during the night whereas fish prey were eaten during daylight. This supports the idea that the diel pattern observed here for whiting was regulated by changes in the availability of the prey.

The diel change in the intake of the different prey has important implications for the functional response of the predator to changes in prey availability. In traditional prey selection models, the diet of the predator is assumed to reflect the relative density of the different prey types (Murdoch et al. 1975) or the density of 
the more preferred prey types (Stephens \& Krebs 1986). However, if feeding is effectively divided into 2 separate periods, an increase in the abundance of 'daytime' prey will not affect the relative density of 'nighttime' prey experienced by the predator. Any effect would have to be mediated through satiation of the predator. The response of the predators to changes in food availability is thus unlikely to follow traditional food selection models, and further studies are needed to determine in detail how the diet of the predators depends on the availability of such temporally segregated prey.

Acknowledgements. I am deeply indebted to H. Gislason and P. Degnbol who collected the stomach data and placed them at my disposition, and to A. D. Hansen, who examined the stomach contents so thoroughly. H. Gislason, M. Vinther and 2 anonymous referees provided valuable comments on an earlier draft. This study was partly funded by a grant from the Danish Ministry of Food, Agriculture and Fisheries to the project 'Development of improved models of fisheries impact on marine fish stocks and ecosystems' (FIFOF-DFU-1). The research was supported by the SLIP research school under the Danish Network for Fisheries and Aquaculture Research (www.fishnet.dk) financed by the Danish Ministry for Food, Agriculture and Fisheries and the Danish Agricultural and Veterinary Research Council.

\section{LITERATURE CITED}

Adlerstein SA, Welleman HC (2000) Diel variation of stomach contents of North Sea cod (Gadus morhua) during a $24 \mathrm{~h}$ fishing survey: an analysis using generalized additive models. Can J Fish Aquat Sci 57:2363-2367

Aglen A, Misund OA (1990) Swimming behaviour of fish schools in the North Sea during acoustic surveying and pelagic sampling trawling. ICES CM 1990/B:38

Albert OT (1995) Diel changes in food and feeding of small gadoids on a coastal bank. ICES J Mar Sci 52:873-885

Andersen NG (1999) The effects of predator size, temperature, and prey characteristics on gastric evacuation in whiting. J Fish Biol 54:287-301

Ansell AD, Comely CA, Robb L (1999) Distribution, movements and diet of macrocrustaceans on a Scottish sandy beach with particular reference to predation on juvenile fishes. Mar Ecol Prog Ser 176:115-130

Bailey RS (1975) Observations on the diel behaviour patterns of North Sea gadoids in the pelagic phase. J Mar Biol Assoc UK 55:133-142

Bergstad OA (1991) Distribution and trophic ecology of some gadoid fish of the Norwegian Deep. 1. Accounts of individual species. Sarsia 75:269-313

Bergström BI (2000) The biology of Pandalus. Adv Mar Biol 38

Bres M (1989) The effects of prey relative abundance and chemical cues on prey selection in rainbow trout. J Fish Biol 35:439-445

Bromley PJ, Kell LT (1995) Vertical migration patterns and spatial distribution of pelagic 0 -group gadoids (cod, haddock, whiting and Norway pout) in the North Sea. ICES CM 1995/G:27

Buckel JA, Stoner AW (2000) Functional response and switch- ing behavior of young-of-the-year piscivorous bluefish. J Exp Mar Biol Ecol 245:25-41

Chesson J (1978) Measuring preference in selective predation. Ecology 59:211-215

Ehrich S, Gröger J (1989) Diel variation in catchability of several fish species in the North Sea. ICES CM 1989/B:35

Freire J, Fernández L, González-Gurriarán E (1991) Diel feeding pattern of Liocarcinus depurator (Brachyura: Portunidae) in the Ria de Arousa (Galicia, NW Spain). Ophelia 33:165-177

Gordon JDM (1977) The fish populations in inshore waters of the west coast of Scotland. The food and feeding of the whiting (Merlangius merlangus L.). J Fish Biol 11: 513-529

Hagerman L (1970) Locomotory activity patterns of Crangon vulgaris (Fabricius) (Crustacea, Natantia). Ophelia 8: 255-266

Hall SJ, Gurney WSC, Dobby H, Basford DJ, Heaney SD, Robertson MR (1995) Inferring feeding patterns from stomach contents data. J Anim Ecol 64:39-62

Hislop JRG, Robb AP, Bell MA, Armstrong DW (1991) The diet and food consumption of whiting (Merlangius merlangus) in the North Sea. ICES J Mar Sci 48:139-156

Jones R (1954) The food of the whiting and a comparison with that of the haddock. Mar Res Ser Scott Home Dep 2

Liljebladh B, Thomasson MA (2001) Krill behaviour as recorded by acoustic Doppler current profilers in the Gullmarsfjord. J Mar Syst 27:301-313

Manly BFJ, Miller P, Cook LM (1972) Analysis of a selective predation experiment. Am Nat 106(952):719-736

McCullaugh P, Nelder JA (1989) Generalized linear models. Monogr Stat Appl Probab 37. Chapman \& Hall, London

Mergardt N, Temming A (1997) Diel pattern of food intake in whiting (Merlangius merlangus) investigated from the weight of partly digested food particles in the stomach and laboratory determined particle decay functions. ICES J Mar Sci 54:226-242

Michalsen K, Godø OR, Fernö A (1996) Diel variability in the catchability of gadoids and its influence on the reliability of abundance indices. ICES J Mar Sci 53:389-395

Murdoch WW, Avery S, Smyth MEB (1975) Switching in predatory fish. Ecology 56:1094-1105

Naylor E (1958) Tidal and diel rythms of locomotory activity in Carcinus maenas (L.). J Exp Biol 35:602-610

Ona E, Chruickshank O (1986) Haddock avoidance reactions during trawling. ICES CM 1986/B:36

Ona E, Toresen R (1988) Reactions of herring to trawling noise. ICES CM 1988/B:36

Onsrud MSR, Kaartvedt S (1998) Diel vertical migration of the krill Meganyctiphanes norvegica in relation to physical environment, food and predators. Mar Ecol Prog Ser 171: 209-219

Patterson KR (1985) The trophic ecology of the whiting (Merlangius merlangus) in the Irish Sea and its significance to the Manx herring stock. J Cons Int Explor Mer 42: $152-161$

Pedersen J (1999) Diet comparison between pelagic and demersal whiting in the North Sea. J Fish Biol 55:1096-1113

Pedersen J (2000) Food consumption and daily feeding periodicity: comparison between pelagic and demersal whiting in the North Sea. J Fish Biol 57:402-416

Pillar SC, Barange M (1997) Diel variability in bottom trawl catches and feeding activity of the Cape hakes off the west coast of South Africa. ICES J Mar Sci 54:485-499

Rindorf A (2002) The effect of stomach fullness on food intake of whiting in the North Sea. J Fish Biol 61:579-593

Robb AP (1981) Observations on the food and diel feeding 
behaviour of pelagic O-group gadoids in the northern North Sea. J Fish Biol 18:183-194

Robb AP (1992) Changes in the gall bladder of whiting (Merlangius merlangus) in relation to recent feeding history. ICES J Mar Sci 49:431-436

Rosenberg R, Nilsson HC, Hollertz K, Hellman B (1997) Density-dependent migration in an Amphiura filiformis (Amphiuridae, Echinodermata) infaunal population. Mar Ecol Prog Ser 159:121-131

Singh-Renton S, Bromley PJ (1999) Feeding of small whiting (Merlangius merlangus) in the central and southern North Sea. J Mar Biol Assoc UK 79:957-960

Editorial responsibility: Otto Kinne (Editor), Oldendorf/Luhe, Germany
Sköld M (1998) Escape responses in four epibenthic brittle stars (Ophiuroidea: Echinodermata). Ophelia 49:163-179

Stefánsson G, Pálsson OK (1997) Statistical evaluation and modelling of the stomach contents of Icelandic cod (Gadus morhua). Can J Fish Aquat Sci 54:169-181

Stephens DW, Krebs JR (1986) Foraging theory. Princeton University Press, Princeton, NJ

Tarling G, Burrows M, Matthews J, Saborowski R, Buchholz F, Bedo A, Mayzaud P (2000) An optimization model of the diel vertical migration of northern krill (Meganyctiphanes norvegica) in the Clyde Sea and the Kattegat. Can J Fish Aquat Sci 57 (Suppl 3):38-50

Submitted: November 28, 2001; Accepted: November 6, 2002 Proofs received from author(s): February 20, 2003 